\title{
Higher self-reported physical activity Is associated with lower systolic blood pressure: The Dietary Intervention Study in Childhood (DISC)
}

Samuel S. Gidding

Thomas Jefferson University and A.I. duPont Hospital for Children

Bruce A. Barton

Maryland Medical Research Institute

Joanne A. Dorgan

Fox Chase Cancer Center

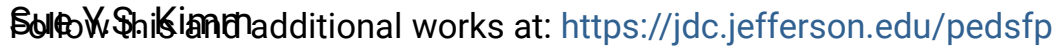

diversity of Pittsburgh

Part of the Bioethics and Medical Ethics Commons

Peet Qiswikfroviah how access to this document benefits you Johns Hopkins University

\section{Recommended Citation}

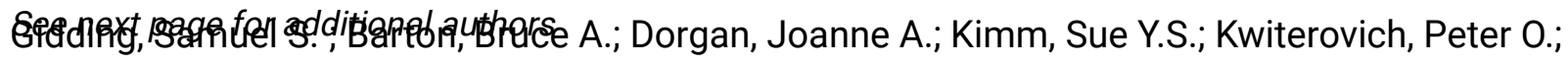

Lasser, Normal L.; Robson, Alan M. ; Stevens, Victor J.; Van Horn, Linda; and Simons-Morton, Denise G., "Higher self-reported physical activity Is associated with lower systolic blood pressure: The Dietary Intervention Study in Childhood (DISC) " (2006). Department of Pediatrics Faculty Papers. Paper 3.

https://jdc.jefferson.edu/pedsfp/3

This Article is brought to you for free and open access by the Jefferson Digital Commons. The Jefferson Digital Commons is a service of Thomas Jefferson University's Center for Teaching and Learning (CTL). The Commons is a showcase for Jefferson books and journals, peer-reviewed scholarly publications, unique historical collections from the University archives, and teaching tools. The Jefferson Digital Commons allows researchers and interested readers anywhere in the world to learn about and keep up to date with Jefferson scholarship. This article has been accepted for inclusion in Department of Pediatrics Faculty Papers by an authorized administrator of the Jefferson Digital Commons. For more information, please contact: JeffersonDigitalCommons@jefferson.edu. 


\section{Authors}

Samuel S. Gidding, Bruce A. Barton, Joanne A. Dorgan, Sue Y.S. Kimm, Peter O. Kwiterovich, Normal L. Lasser, Alan M. Robson, Victor J. Stevens, Linda Van Horn, and Denise G. Simons-Morton 
Higher Self Reported Physical Activity is Associated with Lower Systolic Blood Pressure: The Dietary Intervention Study in Childhood (DISC)

Samuel S. Gidding MD, Bruce A. Barton PhD, Joanne Dorgan PhD, Sue Y. S. Kimm MD, Peter O. Kwiterovich MD, Normal L. Lasser MD, PhD, Alan M. Robson MD, Victor J. Stevens PhD, Linda Van Horn PhD, Denise G. Simons-Morton MD, PhD

From

Nemours Cardiac Center, A.I. duPont Children's Hospital and Thomas Jefferson University, Wilmington, DE (SSG)

Maryland Medical Research Institute, Baltimore MD (BAB)

Fox Chase Cancer Center, Philadelphia, PA (JAD)

University of Pittsburgh, Pittsburgh, Pa (SYSK)

Johns Hopkins University, Baltimore, MD (POK)

New Jersey Medical School, Newark, NJ (NLL)

Children's Hospital, New Orleans, LA (AMR)

Kaiser-Permanente Center for Health Research, Portland, OR (VS)

Northwestern University Medical School, Chicago, IL (LVH)

National Heart, Lung, and Blood Institute, Bethesda, MD (DGSM)

Correspondence:

Samuel S. Gidding, MD

Nemours Cardiac Center

1600 Rockland Road

Wilmington, DE 19899

Sgidding@nemours.org

$3026516600(5345$, fax $)$

Reprint requests:

Bruce A. Barton, Ph.D.

Maryland Medical Research Institute

600 Wyndhurst Ave.

Baltimore, MD 21210 
None of the authors have a conflict of interest to report regarding the material contained in this manuscript.

Support:

This work was supported by Cooperative Agreements U01-HL37947, U01-HL37948, U01-HL37954, U01-HL37962, U01-HL-37966, U01-HL37975, and U01-HL38110 from the National Heart, Lung, and Blood Institute, National Institutes of Health.

Dr. Gidding is supported by the COBRE Award \# 1 P20 RR020173-01

Keywords:

Blood Pressure

Physical Fitness

Cardiovascular Disease

Abbreviations:

Systolic blood pressure (SBP) Low density lipoprotein (LDL)

Body mass index (BMI)

Dietary Intervention Study in Children (DISC)

Generalized Estimating Equation (GEE)

Estimated metabolic equivalent (MET) 


\begin{abstract}
Objective: Children participating in a dietary clinical trial were studied to assess physical activity patterns in boys and girls longitudinally from late childhood through puberty; and to determine the association of level of physical activity on systolic blood pressure (SBP), low density lipoprotein (LDL) cholesterol, and body mass index (BMI).
\end{abstract}

Patients and Methods: In the Dietary Intervention Study in Childhood (DISC), a randomized clinical trial of a reduced saturated fat and cholesterol diet in 8-10 year olds with elevated LDL, a questionnaire that determined time spent in five intensity levels of physical activity was completed at baseline and at 1 and 3 years. A MET score was calculated for weekly activity; hours per week were calculated for intense activities. We hypothesized that weekly self-reported physical activity would be associated with lower SBP, LDL, and BMI over three years. Longitudinal data analyses were performed for each outcome (SBP, LDL, and BMI) using generalized estimating equations with MET score per week as the independent variable adjusted for visit, gender, and Tanner stage (BMI was included in models for SBP and LDL). Results: The initial study cohort comprised 663 youths (362 male; age 9.7 years, 301 female; age 9.0 years) of whom 623 (94\%) completed the 3-year visit. For every 100 MET-hours of physical activity, there was a decrease of $1.15 \mathrm{mmHg}$ of SBP $(\mathrm{p}=0.0038)$. There was a $1.28 \mathrm{mg} / \mathrm{dl}$ decline in LDL $(\mathrm{p}=0.10)$ for a similar energy expenditure. For BMI, an analysis of intense physical activity showed that for every 10 hours of intense activity, there was a trend toward significance with a $0.2 \mathrm{~kg} / \mathrm{m}^{2}$ decrease $(\mathrm{p}=0.06)$.

Conclusion: Children with elevated cholesterol who lead a more physically active lifestyle have lower SBP and a trend toward lower LDL over a 3-year interval. Long-term participation in 
intense physical activity may reduce BMI as well. 


\section{Introduction}

Physical activity is thought to be associated with cardiovascular risk factors at all ages; but there are very few longitudinal data on this relationship in children and adolescents. (1) Several cross-sectional, observational, and short-term intervention studies have explored the relationship of physical activity and/or fitness to cardiovascular risk factors; these have generally shown small positive results or been inconclusive. (2-5) Two longitudinal studies have shown small but significant relationships of blood pressure and cholesterol to physical activity participation following sustained intervention over one to two years. No observational studies have assessed physical activity in relation to cardiovascular risk in boys and girls longitudinally from late childhood through puberty.

The Dietary Intervention Study in Childhood (DISC) was a three-year randomized trial in children with elevated low density lipoprotein (LDL) cholesterol, 8-10 years of age at initial evaluation, that tested effects of an intervention to promote a reduced saturated fat/reduced cholesterol diet on LDL-cholesterol levels. (6) At three time points (baseline, year one, and year three), an interviewer administered a questionnaire to assess regular physical activity over the course of a full week. The purpose of the current analysis is to assess the relationship between regular physical activity and LDL-cholesterol, blood pressure, and body mass index (BMI) over the first 3 years of the DISC study. We hypothesized that increased physical activity would be associated with lower blood pressure, LDL cholesterol, and BMI.

\section{Methods}

DISC was a collaborative six-center randomized controlled trial of lowering LDL cholesterol by a dietary educational and behavioral intervention in pre-pubertal children with 
elevated cholesterol at initial evaluation. The study was approved by the Institutional Review Boards of all participating centers and by an NHLBI-appointed Data and Safety Monitoring Board. Parents provided informed consent.

DISC eligibility criteria, baseline characteristics, study design, and intervention have been described in detail elsewhere. (6) In brief, DISC required baseline LDL cholesterol levels between the $80^{\text {th }}$ and $98^{\text {th }}$ percentiles for age and gender based on the Lipid Research Clinics data set. Because no evidence for pubertal development could be present, recruitment age was set at 8 years and 6 months through 10 years 10 months for boys and 7 years 10 months to 10 years 1 month for girls. Major illnesses and taking lipid lowering medications were exclusion criteria. Blood pressure level $>125 / 80 \mathrm{~mm} \mathrm{HG}$ and weight for height either $<5^{\text {th }}$ percentile or $>90^{\text {th }}$ percentile based on data from the Bogalusa heart Study were additional exclusion criteria. For every 100 children screened, 2 were enrolled in the study.

DISC participants were randomly assigned to treatment $(\mathrm{n}=334)$ or usual care $(\mathrm{n}=329)$. The intervention consisted of individual, group, and family education to achieve dietary goals of $\leq 28 \%$ of calories from total fat, $<8 \%$ of calories from saturated fat, and $<150 \mathrm{mg} /$ day of cholesterol.(7) Though exercise was encouraged in the intervention group and in the usual care group, exercise was not a formal component of the intervention.

This report presents an analysis of all DISC participants who had data on physical activity, blood pressure, LDL-cholesterol, and BMI on at least one of three time points, baseline, 1 year, and 3 years. The DISC data set was collected between 1987 and 1991. 


\section{Data Collection}

An interviewer-administered recall questionnaire was designed to capture physical activity for a full 24 hours each day for a period of a week. (8) The questionnaire was administered twice, to collect data for weekdays and weekends. Amount of time spent in physical activities was collected for each of five activity intensity levels. An estimated metabolic equivalent (MET) score was calculated by multiplying the number of hours spent at each level of activity intensity by a MET (multiple of resting energy expenditure) for that intensity level. The levels and MET scores used were: sleeping (1 MET), sedentary (1.5 METS), light (4 METS), moderate (6 METS), and intense (10 METS). Specific examples of activities were provided for each intensity level to guide assignment. The weekday score was multiplied by 5 and the weekend score was multiplied by 2; the sum represented a weekly MET score, which can be interpreted as MET-hours per week. For example, over a week, a participant who ran for 4 hours (intense 10 METS), walked briskly for 14 hours (moderate 6 METS), spent 64 hours in standing activities or light household chores (light 4 METS), slept 8 hours a night (56 hours at 1 MET), and spent the remainder of the time sitting at school or watching TV (1.5 METS), would have a MET score of 481.

Blood pressure was measured at rest twice using a Hawksley random-zero sphygmomanometer, and the average measure, after correction for the random zero, was used. Korotkoff phase IV was used for diastolic blood pressure. Height was measured with shoes off in centimeters with stadiometers constructed by the Medical Instruments Unit of the University of Iowa. Weight in light clothing was measured in kilograms using scales calibrated weekly. Strict quality assurance measures were employed to guarantee measurement accuracy. Each 
measurement was made twice and averaged; if agreement was poor a third measurement was made. Lipids and lipoproteins were measured in a CDC standardized laboratory (Johns Hopkins University) using enzymatic procedures. LDL cholesterol was calculated using the Friedewald equation.

\section{Data analysis}

Descriptive statistics were calculated for all study variables and are presented by gender. Histograms for change in MET score over time were generated. Initially, analyses included an interaction term for treatment group assignment. Since this term was non-significant, data from the two treatment groups were merged, and those results are reported.

Generalized Estimating Equations (GEE) were used to identify the relationship between risk factors as continuous outcomes (blood pressure, LDL-cholesterol, and BMI) and selfreported physical activity. The analyses were implemented using PROC GENMOD in SAS version 9.1 (2002-2003, SAS Institute, Cary, NC), taking into account clustering due to multiple measurements per participant with appropriate distribution and link functions to model the continuous outcomes and the continuous predictor variable self-reported physical activity (MET score or hours in intense activity). Type III Wald $\chi^{2}$ tests were used to test the significance of predictors in the GEE models. Additional analyses were performed to determine if specific components of the score (hours in moderate or intense activity) were independently associated with an effect. Models for diastolic blood pressure, triglycerides, and HDL cholesterol were created but no significant relationships were obtained (data not shown).

\section{Results}

The characteristics of the cohort for critical study variables are presented in Table I (boys) and Table II (girls). LDL-C values are at the high end of the normal distribution per the 
study protocol. About half the cohort entered puberty by year 1, and very few were prepubertal at year 3 .

MET scores for males and females are presented in Tables III and IV. MET scores were similar for both genders with boys having slightly higher scores at baseline and scores increasing slightly from exam to exam. The gender difference may be explained by the fact that boys participated in slightly more intense activity (Figure 1); participation in moderate activity was similar in both genders (Figure 2).

Results of the GEE analyses showing associations between physical activity and cardiovascular risk factors are presented in Table V. The most important finding is the relationship between systolic blood pressure and activity level. A 100 unit higher MET score was associated with a $1.15 \mathrm{mmHg}$ decline in systolic blood pressure. There was a trend towards a $1.28 \mathrm{mg} / \mathrm{dl}$ lower LDL-cholesterol with a similar change in activity. No relationship between MET score and BMI was obtained but a trend towards a lower BMI was observed in relation to time spent in intense activity.

The mean change in MET score by gender is shown in Figure 3. Though the median change in score is slightly $>0$ units, there was a wide variation in MET score from visit to visit. The difference between the upper and lower quartile of the distribution is 75 units and the difference from the $95^{\text {th }}$ percentile or $5^{\text {th }}$ percentile to the median is about 100 units.

\section{Discussion}

This study shows a significant relationship in the direction of improved cardiovascular risk factors between self reported level of physical activity and systolic blood pressure over a three-year interval in children going through puberty. Trends were observed towards lower LDL 
cholesterol, and, for participation in intense activity, BMI. These data are supportive of current recommendations for increased participation in physical activity to prevent development of cardiovascular risk factors. (9) Since children's blood pressures normally increase 1-2 $\mathrm{mmHg} / \mathrm{year}$, the benefit from prevention over a three-year interval of a $1 \mathrm{mmHg}$ rise in systolic blood pressure, as observed in this study, has potential public health significance.(10)

The DISC study adds to the literature on longitudinal assessment of the relationship of physical activity to cardiovascular risk factors in children. A comparable study is the Northern Ireland Young Hearts Project that assessed cardiovascular risk in a random cohort of school children at 12 and 15 years of age.(2) That study showed a significant relationship between increased self-reported physical activity and lower blood pressure over the three year interval. In the Muscatine Study, a small subset of the cohort (mean age 10 years at the onset of the study) underwent rigorous measurement of physical fitness over a 5 year interval.(4) Measures of fitness and strength showed relationships to lipid levels, adiposity, and blood pressure over the follow up interval. In a study of 5 year old inner city children followed for an average of 19 months, Shea et al showed that the age related rise in blood pressure was attenuated by increased aerobic fitness or decreased body mass index.(3)

There have been several randomized controlled trials examining effects of controlled physical activity interventions on blood pressure in children, and these have recently been reviewed.(5) Interventions were generally conducted over several months, with the longest study carried out for 36 weeks. Sample sizes varied widely with most studies having between 16 and 188 participants; however 2 had sample sizes of 500 or larger. These studies showed collectively a 1-3\% reduction in blood pressure of marginal statistical significance; the types of interventions varied widely from weight training to regular aerobic activity programs to participation in 
activity related games and other activities. The magnitude of effect is similar to that shown in our study. Though the magnitude of change in blood pressure with increased activity is not sufficient to treat established hypertension, intervention studies and longitudinal studies such as this one all suggest that the age-related rise in blood pressure may be blunted by frequent or increased physical activity participation. (10) The change in activity associated with a significant change in systolic blood pressure, though large, did occur spontaneously among DISC participants over the course of the study.

The current study did not show a significant relationship between self reported total physical activity and BMI. However, since significant obesity was an exclusion criteria for study participation, and very few of the children in this study became overweight, it would be a misinterpretation of the data to suggest that physical activity participation is not useful in either obesity treatment or prevention. The trend towards lower BMI with participation in intense activity does suggest that regular participation in vigorous activities may play a role in obesity prevention; in adolescent girls physical activity participation is directly related to acquisition of obesity. (11) In this study BMI was an average of 3 units lower in girls classified as "active" compared with those "inactive" over a 10-year follow-up period. (11) A study of successful weight reduction in adolescents showed a significant reduction in blood pressure (about 10 $\mathrm{mmHg}$ ) when body mass index was reduced about $10 \%$ using both a diet and exercise intervention.(12)

Some intervention studies that have related measured change in physical fitness to risk factors have shown risk factor reduction, others have reported no change, while none have shown adverse changes. (13-17) Recently, exercise intervention studies in overweight children have shown favorable effects of regular exercise on markers of inflammation, insulin sensitivity, 
endothelial function, and vascular reactivity.(18-22) Population-based studies of children in schools have shown associations of higher BMI with sedentary activity, and prevention of the acquisition of overweight with regular increases in scheduled physical education classes. (23, 24) Cross sectional studies in children have generally shown that participation in physical activity improves cardiovascular risk factors. Results are often inconsistent, however, with some studies showing positive effects on blood pressure whereas others show benefit with respect to dyslipidemia. No studies have shown statistically significant adverse effects of increased physical activity on cardiovascular risk.(25-28)

Though our study showed that physical activity has a statistically significant benefit on cardiovascular risk factors, particularly systolic blood pressure, the change in physical activity required to produce a measurable change is large. These data support the development of clinical trials to test whether public health efforts to increase regular physical activity lead to long-term attenuation of the rise of systolic blood pressure over time. It would be interesting to compare results using newer methods of physical activity assessment, such as accelerometers, to results from questionnaires to determine if these newer methods show stronger correlations with risk factors.(29)

An important component of the DISC study was data collection with rigorous quality control procedures.(6) This high quality data set allowed for careful analysis of subtle effects of physical activity on risk. A second advantage is the relatively large sample size, over 600 children. A third advantage is the relatively narrow age range with all children being prepubertal at baseline.

The major limitation of the DISC cohort is the highly selective enrollment criteria. The DISC cohort represents a generally middle to upper middle class group of families with an 
interest in participating in a three-year rigorous dietary intervention, rather than a population based sample. Elevated LDL-cholesterol was required. Extremes of the BMI distribution were excluded. The finding in this study that physical activity increased over time - including overall, moderate, and vigorous intensity - are not consistent with other studies. For example, in the population-based National Growth and Health Study, conducted simultaneously, physical activity declined substantially over time, and this decline was associated with an increased prevalence of obesity. $(29,30)$ This difference in pattern over time may suggest that this highlyselected cohort was not representative, which may have led to a narrower variation in daily physical activity, perhaps contributing to an underestimation of the effect.

In summary, this study showed beneficial long-term effects of increased physical activity on cardiovascular risk factors in developing children. Of particular importance is the potential of higher levels of participation in physical activity to counteract age-related increases in systolic blood pressure, potentially, dyslipidemia and BMI. Increased physical activity in youth is a critical component of primordial prevention of heart disease, i.e., the prevention of risk factor acquisition.(19)

Acknowledgments

This research was supported by the National Heart, Lung, and Blood Institute cooperative agreements HL-37947, HL-37948, HL-37954, HL-37962, HL-37966, HL-37975, and HL-38110.

Dr. Gidding acknowledges support of Grant Number 1 P20 RR020-173-01 from the National Center for Research Resources (NCRR), a component of the National Institutes of Health (NIH). 


\section{References}

1. Williams CL, Hayman LL, Daniels SR, et al. Cardiovascular health in childhood: A statement for health professionals from the Committee on Atherosclerosis, Hypertension, and Obesity in the Young (AHOY) of the Council on Cardiovascular Disease in the Young, American Heart Association. Circulation 2002;106(1):143-60.

2. Boreham C, Twisk J, van Mechelen W, Savage M, Strain J, Cran G. Relationships between the development of biological risk factors for coronary heart disease and lifestyle parameters during adolescence: The Northern Ireland Young Hearts Project. Public Health 1999;113(1):7-12.

3. Shea S, Basch CE, Gutin B, et al. The rate of increase in blood pressure in children 5 years of age is related to changes in aerobic fitness and body mass index. Pediatrics 1994;94(4 Pt 1):465-70.

4. Janz KF, Dawson JD, Mahoney LT. Increases in physical fitness during childhood improve cardiovascular health during adolescence: the Muscatine Study. Int J Sports Med 2002;23 Suppl 1:S15-21.

5. Kelley GA, Kelley KS, Tran ZV. The effects of exercise on resting blood pressure in children and adolescents: a meta-analysis of randomized controlled trials. Prev Cardiol 2003;6(1):8-16.

6. Dietary intervention study in children (DISC) with elevated low-density-lipoprotein cholesterol. Design and baseline characteristics. DISC Collaborative Research Group. Ann Epidemiol 1993;3(4):393-402.

7. Stevens VJ, Obarzanek E, Franklin FA, et al. Dietary intervention study in children (DISC): Intervention design and participation. J Nutr Educ 1995;27(3):133-40.

8. Sallis JF, Haskell WL, Wood PD, et al. Physical activity assessment methodology in the Five-City Project. Am J Epidemiol 1985;121(1):91-106.

9. Physical activity and health: a report of the surgeon general: U.S. Department of Health and Human

Services

$\mathrm{CDC}$

National Center for Chronic Disease Prevention and Health Promotion

The President's Council on Physical Fitness and Sports; 1996.

10. The fourth report on the diagnosis, evaluation, and treatment of high blood pressure in children and adolescents. Pediatrics 2004;114(2 Suppl 4th Report):555-76.

11. Kimm SY, Glynn NW, Obarzanek E, et al. Relation between the changes in physical activity and bodymass index during adolescence: a multicentre longitudinal study. Lancet 2005;366(9482):301-7.

12. Becque MD, Katch VL, Rocchini AP, Marks CR, Moorehead C. Coronary risk incidence of obese adolescents: reduction by exercise plus diet intervention. Pediatrics 1988;81(5):605-12.

13. Hansen HS, Froberg K, Hyldebrandt N, Nielsen JR. A controlled study of eight months of physical training and reduction of blood pressure in children: the Odense schoolchild study. Bmj 1991;303(6804):682-5.

14. Ewart CK, Young DR, Hagberg JM. Effects of school-based aerobic exercise on blood pressure in adolescent girls at risk for hypertension. Am J Public Health 1998;88(6):949-51.

15. Gutin B, Owens S. Role of exercise intervention in improving body fat distribution and risk profile in children. Am J Human Biol 1999;11(2):237-47.

16. McMurray RG, Harrell JS, Bangdiwala SI, Bradley CB, Deng S, Levine A. A school-based intervention can reduce body fat and blood pressure in young adolescents. J Adolesc Health 2002;31(2):125-32.

17. Korsten-Reck U, Kromeyer-Hauschild K, Wolfarth B, Dickhuth HH, Berg A. Freiburg Intervention Trial for Obese Children (FITOC): results of a clinical observation study. Int J Obes Relat Metab Disord 2004.

18. Kelly AS, Wetzsteon RJ, Kaiser DR, Steinberger J, Bank AJ, Dengel DR. Inflammation, insulin, and endothelial function in overweight children and adolescents: the role of exercise. J Pediatr 2004;145(6):731-6.

19. Gidding SS. One small step for man...? J Pediatr 2004;145(6):719-20.

20. Watts K, Beye P, Siafarikas A, et al. Effects of exercise training on vascular function in obese children. J Pediatr 2004;144(5):620-5.

21. Woo KS, Chook P, Yu CW, et al. Effects of diet and exercise on obesity-related vascular dysfunction in children. Circulation 2004;109(16):1981-6.

22. Prabhakaran B, George D, Patton N, et al. Lifestyle-only Intervention Attenuates the Inflammatory State Associated with Obesity - A Randomized Controlled Study in Adolescents. Journal of Pediatrics 2005; in press.

23. Datar A, Sturm R. Physical education in elementary school and body mass index: evidence from the early childhood longitudinal study. Am J Public Health 2004;94(9):1501-6.

24. Patrick K, Norman GJ, Calfas KJ, et al. Diet, physical activity, and sedentary behaviors as risk factors for overweight in adolescence. Arch Pediatr Adolesc Med 2004;158(4):385-90. 
25. Katzmarzyk PT, Malina RM, Bouchard C. Physical activity, physical fitness, and coronary heart disease risk factors in youth: the Quebec Family Study. Prev Med 1999;29(6 Pt 1):555-62.

26. Boreham CA, Twisk J, Savage MJ, Cran GW, Strain JJ. Physical activity, sports participation, and risk factors in adolescents. Med Sci Sports Exerc 1997;29(6):788-93.

27. Craig SB, Bandini LG, Lichtenstein AH, Schaefer EJ, Dietz WH. The impact of physical activity on lipids, lipoproteins, and blood pressure in preadolescent girls. Pediatrics 1996;98(3 Pt 1):389-95.

28. Guerra S, Ribeiro JC, Costa R, Duarte J, Mota J. Relationship between cardiorespiratory fitness, body composition and blood pressure in school children. J Sports Med Phys Fitness 2002;42(2):207-13.

29. Puyau MR, Adolph AL, Vohra FA, Butte NF. Validation and calibration of physical activity monitors in children. Obes Res 2002;10(3):150-7.

30. Kimm SY, Glynn NW, Kriska AM, et al. Decline in physical activity in black girls and white girls during adolescence. N Engl J Med 2002;347(10):709-15. 


\section{Figure legends}

\section{Figure 1}

Hours/week of participation in intense activity at each examination by gender are shown.

Figure 2

Hours/week of participation in moderate physical activity at each examination by gender are shown.

Figure 3

The mean change in MET score by gender between examinations is shown. 